\title{
Effect of length of oblique lines and prominence of the horizontal line on the decrement of the Müller-Lyer illusion with extended practice '
}

\author{
ROBERT E, DEWAR \\ THE UNIVERSITY OF CALGARY
}

Extended practice (500 trials) in judging the Müller-Lyer figure led to a decrement in the magnitude of the illusion. Although the illusion did not disappear, as earlier investigators had reported, it did approach zero when the figure was drawn so that the horizontal line was more prominent than the oblique lines.

The magnitude of the Müller-Lyer illusion has been found to be directly related to the length of the oblique lines relative to the length of the horizontal line and inversely related to the angle between the oblique lines (Dewar, 1967a) and the prominence of the horizontal line (Dewar, 1965). In addition, the magnitude of the illusion decreases more slowly with practice when the figure is drawn with a large angle between the obliques or with a horizontal line that is more prominent than the obliques. However, this practice decrement is unrelated to the length of the oblique lines (Dewar, 1965).

Since some configurations of the Muller-Lyer figure produce a more rapid practice decrement than do others, this suggests the possibility that the illusion may disappear with extended practice under some conditicns but not others. In the first systematic study of the practice decrement of this lllusion Judd (1902) found that the lllusion disappeared in less than 1000 trials. Köhler \& Fishback (1950) reported that the illusion disappeared in an average of approximately 103 trials for five Ss.

In a recent investigation Dewar (1967b) found that although the illusion produced by a figure with a small angle between the oblique lines decreased more rapidly, the magnitude of the illusion produced by both a small-angled and a large-angled figure reach an asymptote after approximately 500 trials.

The purpose of the present experiments was to examine the influence of two other characteristics of the Müller-Lyer figure-length of the oblique lines and prominence of the horizontal line-on the decrement of the illusion with extended practice. Since an earlier experiment (Dewar, 1967b) had indicated no decrement in the illusion beyond 500 trials, It was decided to administer that number of trials in the present experiments.

\section{Apparafus and procedure}

\section{EXPERIMENT 1}

The apparatus consisted of a rectangular wooden panel $48 \mathrm{in}$. wide and $26 \mathrm{in}$. high, to the center of which was attached the stimulus (the Muller-Lyer figure). The horizontal segment of the figure was $20 \mathrm{~cm}$ in length. Through a series of strings and pulleys the center arrowhead of the Müller-Lyen figure could be moved in either direction by $\mathrm{E}$ or by $S$. Details of the apparatus and procedure are described in an earlier paper (Dewar, 1967a). The apparatus was set on a table 60 in. from S's head, which was held in a chin rest. $S$ was instructed to adjust the center arrowhead so that the two horizontal segments of the figure appeared to be equal in length. At the beginning of each trial, the adjustable center arrowhead was set by $E$ obviously too far to the right or left of the center position.

The Ss assigned to the two experimental groups at random judged the figure 100 times per day on five consecutive days. The oblique lines of the arrowheads formed an angle of $60^{\circ}$, but were of different lengths for the two groups. One group of $16 \mathrm{Ss}$ (eight male and eight female) judged a figure with $1 \mathrm{~cm}$ oblique lines, while the other group of $16 \mathrm{Ss}$ fudged a figure with $3 \mathrm{~cm}$ oblique lines. All Ss were paid $\$ 1.25$ per session.

Subjects

The Ss were undergraduate university students at The University of Calgary. Their mean age was 22.5 years.

Results

Each S's trials were divided into blocks of 10 for the purpose of analysis. An analysis of variance indicated a substantial decrease in the illusion with practice $(F=4.52$, df $=49 / 1470, p<.001$ ), but no difference in the magnitude of the lllusion due to the length of the oblique lines nor a length by trials interaction. The illusion produced by the $1 \mathrm{~cm}$ figure showed a marked decrement within the first day, and very little change beyond that point (see Fig. 1). The illusion produced by the $3 \mathrm{~cm}$ figure, however, decreased gradually from day to day. Separate analyses done on the data from each session indicate a practice decrement $(F=6.63, d f=9 / 270, p<.001)$ during the first session, but no decrement within sessions beyond the first day. The mean illusion did not approach zero for either figure. However, for four Ss the illusion did disappear and become negative.

\section{EXPERIMENT 2}

The apparatus and procedure were identical to those used in the previous experiment, with the ex- 
ception of the stimulus figures used. In this experiment both figures were drawn with oblique lines $3 \mathrm{~cm}$ in length and forming a $60^{\circ}$ angle. The oblique lines were painted light gray for both figures, but one group of $16 \mathrm{Ss}$ judged a figure with a black horizontal line, while the other group of 16 Ss judged a figure with a light gray horizontal line (the same shading as the oblique lines).

Resulis

Both figures produced a decrement in the magnitude of the illusion with practice (Fig. 2). The analysis of variance indicated a practice effect $(F=5.36, \mathrm{df}=$ $49 / 1470, p<.001)$, a difference in the magnitude of the illusion produced by the two figures $(F=7.79, \mathrm{df}=$ $1 / 30, p<.01)$, but no interaction between figure and trials. The light gray figure produced a greater illusion than did the black figure. Separate analyses of variance performed on the data for each day indicated that there was no practice decrement within any of the daily sessions. Although the illusion did not disappear, that of the group judging the figure with a black horizontal line did approach zero, with a mean of $2 \mathrm{~mm}$ of illusion (which represents a $2 \%$ error) in the fifth session. The illusion did disappear and become negative for six of the Ss.

\section{DISCUSSION}

The results of these two experiments do not conflrm earlier reports by Köhler \& Fishback (1950) that the Muller-Lyer illusion disappears with extended practice. However, the data from Ss who judged the figure with a black horizontal line agree fairly closely with the findings of Judd (1902) who reported that the illusion disappeared for one $S$ in

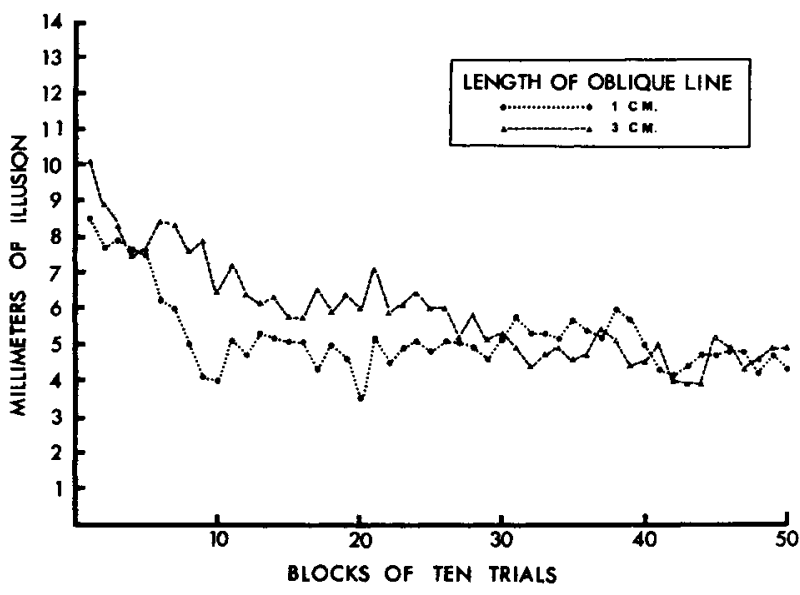

Fig. 1. Magnitude of illusion as a function of practice and length of oblique lines.

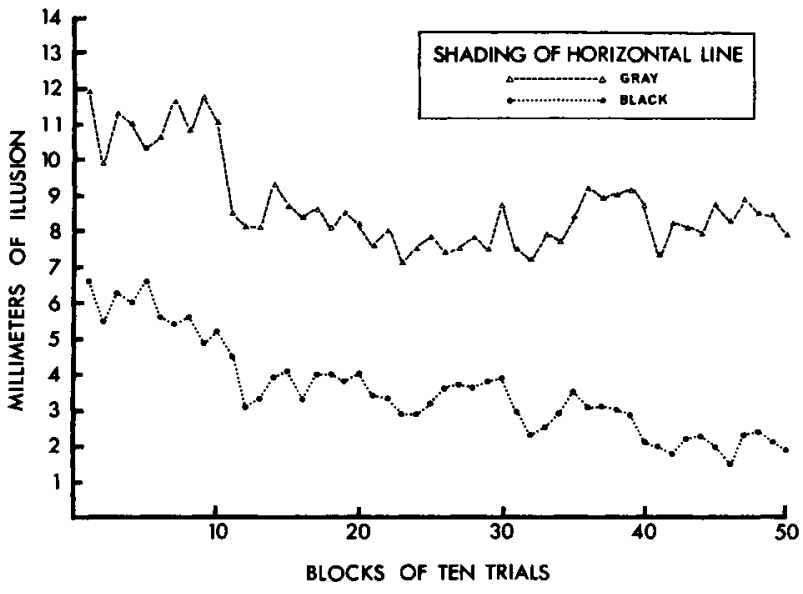

Fig. 2. Magnitude of illusion as a function of practice and shading of horizontal line.

600 trials. The mean illusion on the last session for Ss in that group was $2.05 \mathrm{~mm}$, which is really very small. This may be due to the fact that the initial illusion was relatively small for this group $16.7 \mathrm{~mm}$ in the first block of trials) due to the nature of the figure-the ease of isolating and judging the horizontal line which was much more prominent than the obliques. The illusion produced by this figure may have decreased even further with more trials, since it decreases consistently from session to session. This may not apply, however, to the other figures, since all three appear to have reached an asymptote by the final session. These results point up the need to take into account the stimulus characteristics of the Müller-Lyer flgure when working with either the magnitude or the practice decrement of the lllusion.

\section{References}

Dewar, R. E. Stimulus determinants of the Muller-Lyer illusion and its decrement. Unpublished doctoral dissertation, McMaster University, 1965.

Dewar, R. E. Stimulus determinants of the magnitude of the MuellerLyer illusion. Percept. mot. Skills., 1967a, 24, 708-710.

Dewar, R. E. The effect of angle between the oblique lines on the decrement of the Müller-Lyer illusion with extended practice. Percept. \& Psychophys., 1967b, in press.

Judd, C. H. Practice and its effects on the perception of illusions. Psychol. Rev., 1902, 9, 27-39.

Köhler, W., \& Fishback, Julia. The destruction of the Müller-Lyer illusion in repeated trials: I. An examination of two theories. J. exp. Psychol., 1950, 40, 267-281.

\section{Vote}

1. This research was supported by National Research Council of Canada Grant No. APA-141. 